\title{
Effect of various additives on the low temperature performance of petroleum based asphalt binders
}

\begin{abstract}
Transverse cracking is a prevalent problem that occurs in asphalt pavement binders in cold climates and diminishes the integrity of the road as well as shortens the life span of the road leading to premature failure. Current specification for testing petroleum asphalt binders for transverse and low temperature cracking is not elaborate enough to accurately model the engineering behaviour of the binders. Besides, neat asphalt derived from petroleum crude oil does not seem to perform well at certain low temperatures without some modification to it. Thus, a study was to be undertaken to determine the low temperature behaviour of 60-70 penetration neat binder modified with traditionally used materials such as Crushed Lime Stone Powder (CLP), Hydrated Lime (HL) and Cellulose Oil Palm Fiber (COPF) at temperatures $0{ }^{\circ} \mathrm{C},-5{ }^{\circ} \mathrm{C}$ and $-10^{\circ} \mathrm{C}$. The study was carried using the state of the art Bending Beam Rheometer (BBR) to assess the stiffness value, $\mathrm{m}$ value and deflection level. The tests were performed in accordance with AASHTO T 313-12 specification. The results of the penetration, rotational viscosity and softening point showed that all of the modified binder specimens are within the required range. However, the performance assessments on the modified petroleum binders with additive materials showed a varied nature with CL powder being the best and the COPF the lowest. It was also observed that the crushed lime stone powder had an increase in stiffness, reduction in deflection and m-value.
\end{abstract}

Keyword: Asphalt binder; Additives; BBR; Stiffness; m-value; Deflection 